\title{
Cardiovascular Activities of the Bradykinin System
}

\author{
Jagdish N. Sharma \\ Department of Applied Therapeutics, Faculty of Pharmacy, Health Sciences Center, \\ Kuwait University, P.O. Box 24923, Safat 13110, Kuwait \\ E-mail: j.n.sharma@hsc.edu.kw \\ Received October 30, 2007; Revised March 18, 2008; Accepted March 26, 2008; Published April 14, 2008
}

\begin{abstract}
All the components of the kallikrein-kinin system are located in the cardiac muscle and its deficiency may lead to cardiac dysfunction. In recent years, numerous observations obtained from clinical and experimental models of diabetes, hypertension, cardiac failure, ischemia, myocardial infarction, and left ventricular hypertrophy have suggested that the reduced activity of the local kallikrein-kinin system may be instrumental for the induction of cardiovascular-related diseases. The cardioprotective property of the angiotensin-converting enzyme inhibitors is primarily mediated via a kinin-releasing pathway, which may cause regression of the left ventricular hypertrophy in hypertensive situations. The ability of kallikrein gene delivery to produce a wide spectrum of beneficial effects makes it a promising candidate in treating hypertension and cardiovascular and renal diseases. In addition, stable kinin agonists may also be available in the future as therapeutic agents for cardiovascular and renal disorders. However, there are also possibilities of adverse effects that may be caused by these compounds.
\end{abstract}

KEYWORDS: kallikrein-kinin system, cardioprotection, hypertension, cardiac diseases, angiotensin-converting enzyme inhibitors

\section{INTRODUCTION}

A number of observations focus on the kinins as potential mediators in endogenous, cardiovascular protective mechanisms. This is due to the fact that kallikrein-kinin system (KKS) components are localized in the heart and in the vascular tissues[1,2,3,4,5,6]. Kinins are released during ischemia[7] and cause beneficial cardiac effects[8]. Bradykinin (BK) antagonists worsen ischemia-induced effects[9] and BK can contribute to the cardioprotective effects of preconditioning[10]. On the other hand, the reduction in cardiac infarct size by BK, after preconditioning in rabbits, was prevented by a BK antagonist (Hoe 140) treatment[10]. BK at a dose that has no effect on blood pressure (BP) can prevent left ventricular hypertrophy (LVH) in rats with hypertension caused by aortic banding[11]. Reduction in peripheral and cardiac KKS components may also be the cause of developing high BP in human and experimental animals[12,13,14,15]. In the present review, the current concept on the role of kinins in the cardiovascular system is presented. 


\section{THE KININ SYSTEM}

The kinins are pharmacologically active polypeptides, which are released in the tissues and body fluids as a result if the enzymatic action of kallikreins on kininogens. The kinin family includes BK (Arg-Pro-ProGly-Phe-Ser-Pro-Phe-Arg), kallidin (Lys-Arg-Pro-Pro-Gly-Phe-Ser-Pro-Phe-Arg), and methionyl-lysylBK (Met-Lys-Arg-Pro-Pro-Gly-Phe-Arg). Kallidin and methionyl-lysyl-BK are converted into BK by aminopeptidases present in plasma and urine[16]. Kinins are rapidly ( $<15 \mathrm{sec})$ inactivated by circulating kininases[17].

Kininogens are multifunctional proteins derived mainly from alpha-2 globulin. In humans, the two forms of kininogens are high-molecular-weight kininogen (HMWK) and low-molecular-weight kininogen (LMWK)[18].

These kininogens vary from each other in molecular weight, susceptibility to plasma and tissue kallikreins, and in their physiological properties[19]. They are synthesized in the liver and circulate in the plasma and other body fluids. In addition, there is a T-kininogen in rat plasma, which is considered to be an acute-phase reactant of inflammation[20]. This kininogen releases T-kinin by the enzymatic action of T-kallikrein in rats[21]. Tissue kallikrein is found in various organs, such as the kidney, heart, and synovial tissue[1,2,3,22,23]. These kallikreins differ from one another in molecular weight, biological function, and physicochemical and immunological properties[24]. The tissue kallikrein is synthesized in the cells as a precursor and converted into active form by the cleavage of an amino terminal peptide[25]. Active tissue kallikrein acts on LMWK to release kallidin. The plasma kallikrein is found in circulation in an inactive form, which is known as prekallikrein or Fletcher factor[26]. This inactive prekallikrein is converted to active kallikrein by activated Hageman factor (XIIa)[27]. In addition, plasma kallikrein is able to convert inactive factor XII to XIIa by positive feedback reaction. The plasma prekallikrein and HMWK are present together in a complex form[27]. Factor XIIa and factor XI circulate with HMWK in bound form[29]. In this way, factor XI can be converted into XIa for the participation in the intrinsic coagulation cascade[30]. In immunological reactions, the tissue proteoglycone and mast cell heparin might act as an initiating surface for initial activation of the Hageman factor[31]. It seems that the kinins may be generated in parallel with the formation of thrombin at inflammatory sites, since inactive plasma kallikrein can be activated by coagulant Hageman factor. The tissue kallikrein multigene family comprises a closely related cluster of genes that vary in number between the different mammalian species: 24 genes have been identified in the mouse, 20 in the rat, three in humans, and three in the hamster[24].

Several restriction fragment length polymorphisms (RFLP) have been mapped in the tissue kallikrein gene and their regulatory regions in spontaneously hypertensive rats (SHR)[32]. These findings may reflect a possible difference in the tissue kallikrein gene locus between SHR and normotensive WistarKyoto rats (WKYR). A tissue kallikrein RFLP has been indicated to cosegregate with high BP in the F2 offspring of SHR and normotensive Brown Norway rats crosses[33]. This finding strongly suggests a possibility of SHR. The kininases, kinin inactivating enzymes, are present in the plasma, endothelial cells, and in the tissues to regulate the physiological functions of the kinins in the body. These are known as kininase I, kininase II or angiotensin-converting enzyme (ACE), and enkaphalinase. In plasma, kininase I cleaves the C-terminal arginine of BK to form des-Arg9-BK[34]. Kininase II causes inactivation of BK by releasing pentapeptide (Arg-Pro-Pro-Gly-Phe) and tripeptide (Ser-Pro-Phe) fragments. Fig. 1 shows the kinin formation, activation, and inhibition pathways.

\section{KININ RECEPTORS AND ANTAGONISTS}

Kinins exert their pharmacological actions through the activation of two receptor types, B1 and B2, which have been cloned and belong to the seven transmembrane G-protein coupled receptor families[35]. The kinin B1 receptor displays high affinity and selectivity for kinin metabolites lacking the C-terminal arginine residue, such as des-Arg9-BK. The B1 receptor is rarely expressed in normal tissue, but seems to 


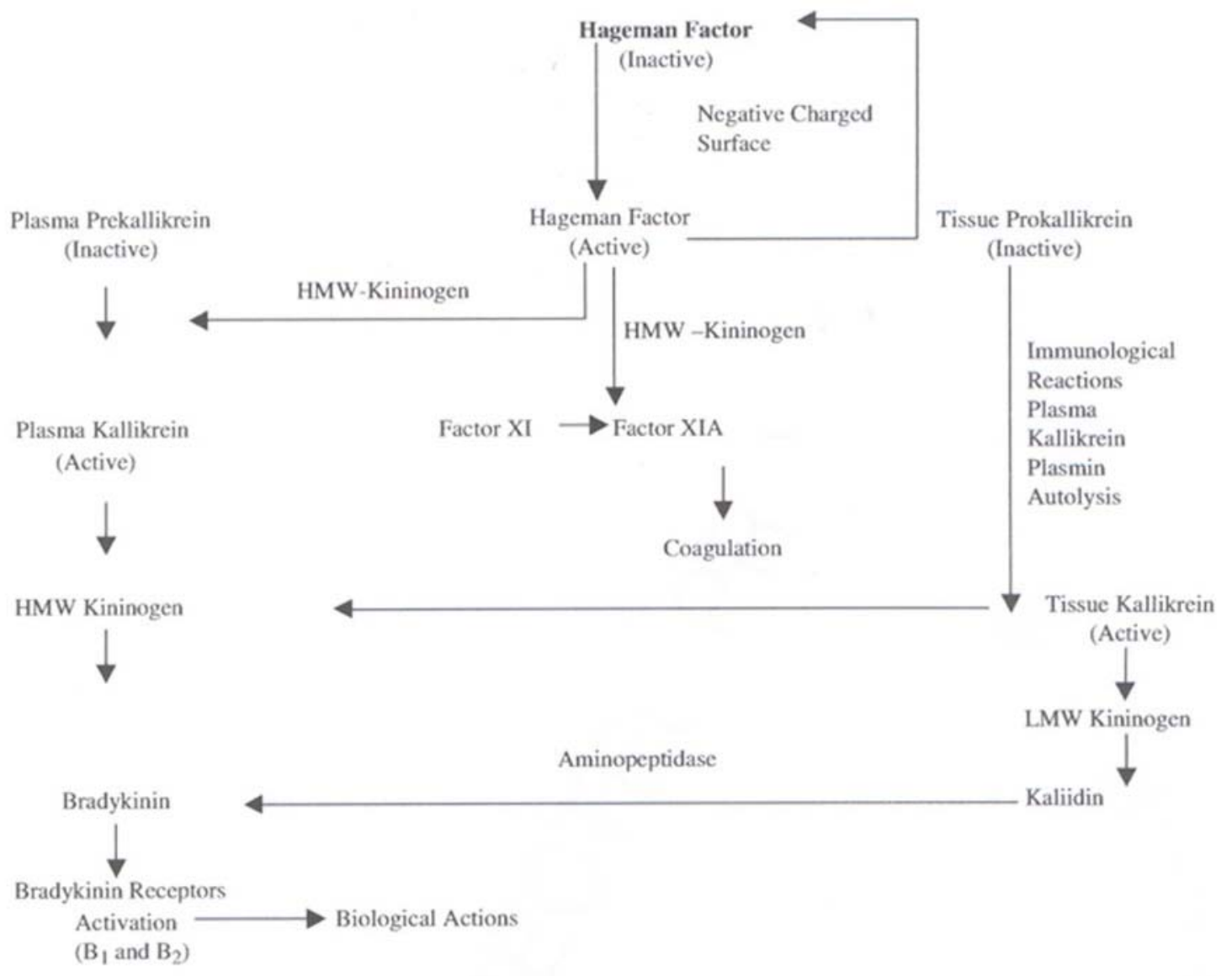

FIGURE 1. The mode of kinin formation.

be up-regulated in pathological states associated with inflammation and tissue injury[35]. This may indicate an important area of research within the study of KKS. B1 receptor activation may produce stimulation of smooth muscle, increased cell proliferation, and collagen synthesis[36]. In addition, it may also the cause release of nitric oxide (NO) and prostacyclin ( $\mathrm{PGI}_{2}$ ) from bovine endothelial cells[37]. Kinins stimulate the release of tumor necrosis factor and interleukin from macrophages through activating B1 receptors[38]. The kinin B2 receptors may participate in pathological conditions, such as pain[39], inflammation[40,41], bronchoconstriction[42], hypertension[43], and cardiac arrhythmias induced in rats[44,45]. The B2 receptor is thought to mediate contractions of rat uterus, guinea-pig ileum, and tracheal smooth muscles[46]. Kinins act on kinin B2 receptors to release conjointly NO and $\mathrm{PGI}_{2}$ from the endothelial cells in vitro[37]. B2 receptors exhibit higher affinity for BK and kallidin. Farmer et al.[47] suggested that the large airways contain a novel B3 receptor, which may produce BK-induced bronchoconstriction. These investigators noted that several B2 receptor antagonists, such as D-Arg (Hyp3,D-Phe-7)-BK and D-Arg(Hyp3, Thi5,8,D-Phe7)-BK, as well as B1 antagonist (des-Arg9 [Leu8]$\mathrm{BK}$ ), did not block the BK-induced contraction of guinea-pig tracheal smooth muscle preparations. The presence of a kinin B3 receptor has also been proposed in the opossum esophageal longitudinal smooth muscle[48]. This receptor has been characterized by rapid desensitization, contraction of longitudinal smooth muscle via PG release, and activation by kinin B2 receptor antagonists (Phe8-D-Phe7-BK and DPhe7-hyp8-BK). Furthermore, Saha et al.[49] proposed the presence of a B4 receptor in the opossum esophageal longitudinal smooth muscle. This receptor shows no tachyphylaxis; its action does not involve PG and it is activated by kinin B2 receptor antagonists (Thi5, 8-D-Phe7, and B6572). The development of kinin receptor antagonists has been pursued for more than 2 decades[50,51]. The kinin B1 receptor 
antagonist was first introduced as des-Arg9-(leu8)-BK by Regoli and Barabe[50]. The "second generation” of B2 receptor antagonist came with the introduction of Hoe 140 (D-Arg-Arg-Pro-Hyp-GlyThi-Ser-D-Tic-Ag; Icatibant)[52] and CP-0127 (B(dArg-Arg-Pro-Hyp-Gly-Phe-Cys-DPhe-LeuArg)2[53]. The "third generation" of BK antagonist, B9430 (DArg-Arg-Pro-Hyp-Gly-Igl-Ser-DIgl-OicArg) is known to be extremely potent and long lasting at both B1 and B2 receptors[54]. The development of this compound not only demonstrates that a polypharmaceutic approach covering both receptor types is possible, but also that the structures of the B1 and B2 receptors are sufficiently similar to be antagonized by a single drug. This fact was not appreciated until recently. Most recently, bradyzide, a potent nonpeptide B2 BK receptor with long-lasting oral activity in animal models of inflammatory hyperalgesia, has been described[55]. These BK receptor antagonists may prove to be therapeutically applicable in pathological states, which are caused by hyperactivity of kinins.

\section{MODE OF THE KININ ACTION}

Interaction between the kinins and their specific receptors can lead to activation of several secondmessenger systems. The kinin receptor stimulation in the intact cells or in tissues appear to initiate the second-messenger pathways, such as arachidonic acid products and the activation of calcium-sensitive systems[56]. The elevation of cellular inositol phosphates by BK involves G-protein coupled activation of phospholipase $\mathrm{A} 2$ and $\mathrm{C}$ that are used in the synthesis of eicosanoids[57]. It is of interest that indomethacin, a cyclooxygenase inhibitor, was able to cause potentiation of BK-induced contractions of both isolated estrous rat uterus and guinea-pig tracheal smooth muscle preparations[58,59]. These findings may suggest that there could be noneicosanoid pathways for the cellular and molecular actions of BK. Furthermore, it is known that BK significantly stimulates phosphoinositide hydrolysis in guinea-pig ileum longitudinal muscle that may result in elevation of cytosolic calcium ion levels to induce contractile responses[60]. Fischer et al.[61] demonstrated that the kinin B2 receptor stimulation causes production of cyclic guanosine monophosphate (cyclic GMP) in cultured porcine aortic endothelial cells. The formation of cyclic GMP may be an important step for the biological actions as well as release of NO evoked by BK in the endothelial cells and in the vascular smooth muscles.

\section{THE KININ SYSTEM IN CARDIOVASCULAR DISORDERS}

\section{Hypertension}

Hypertension is a major risk factor for the development of cardiovascular diseases, such as coronary heart disease, congestive heart failure, and peripheral vascular and renal diseases[13]. There is ample evidence documenting the role of KKS in the pathogenesis of hypertension[15]. The pharmacological action of BK in the regulation of systemic BP was vasodilatation in most areas of the circulation, a reduction of total peripheral vascular resistance, and a regulation of sodium excretion from the kidney[62,63]. When BK is injected into the renal artery, it causes diuresis and natriuresis by increasing renal blood flow[64]. These actions of BK have been attributed to prostaglandin release in the renal circulation[65]. The role of KKS in hypertension was established by Margolius and coinvestigators[65,66] with the observations that urinary kallikrein excretion is significantly reduced in hypertensive patients and hypertensive rats. This led to the suggestion that reduced urinary kallikrein excretion might result from a defect in kinin generation in hypertensive situations. Research on the systemic changes in the KKS has provided further insight regarding the mechanisms of various hypertensive conditions. In this connection, it is known that kininogen levels and a kinin-potentiating factor are reduced in essential and malignment hypertension[67,68,69,70]. It may be possible that the deficiency in plasma HMWK is due to decreased liver synthesis in individuals who develop hypertension after mild exercise[71]. It can be proposed that a deficient KKS might be a significant factor in the pathophysiology of hypertension. In this connection, it 
is suggested that the role of renal KKS is to excrete excess of sodium. Therefore, a reduction in the generation of renal KKS may be the cause of the development of hypertension as a result of sodium accumulation in the body[72,73]. Thus, the development of a compound having renal kallikrein-like activity may serve the purpose of excreting excessive sodium from the kidney. This action may be useful for the treatment of hypertension. Also, it has been demonstrated that transgenic mice that overexpress renal tissue kallikrein were hypotensive and that the administration of aprotinin, a tissue kallikrein inhibitor, restored the BP in the transgenic mice[74]. The suppression of the hypotensive responses of ACE inhibitors by aprotinin in SHR has been documented[75]. These findings highlight a role of tissue kallikrein in the regulation of BP. Recently, it has been proposed that tissue kallikrein gene delivery into various hypertensive models exhibits protection, such as a reduction in high BP, attenuation of cardiac hypertrophy, inhibition of renal damage, and stenosis[76]. These findings may indicate the prospect of this kallikrein gene therapy for cardiovascular and renal pathology. Kininase II (ACE) inhibitors are currently used in the treatment of both clinical and experimental hypertension[77,78,79]. Kininase II inhibitors could lower BP by inhibiting the biodegradation of kinin as well as blocking the formation of angiotension II (Ang II) at the renal site. A calcium-channel blocker, nifedipine, used to treat patients with essential hypertension, can normalize the reduced urinary kallikrein excretion[80]. Our previous investigations demonstrated differential sensitivity for the genetically Dahl-salt-sensitive (DSS) hypertensive and genetically Dahl-salt-resistant (DSR) normotensive rats to the hypotensive action on nifedipine[79]. This might reflect a significantly more important function of diminished renal KKS activity in DSS hypertensive, as compared with the DSR normotensive, rats. It is unknown whether a similar situation may exist in genetically predisposed humans with hypertension. Furthermore, Smith et al.[80] have proposed that women with reduced activity of the renal KKS combined with increased sympathetic drive may be at increased risk of developing pregnancy-induced hypertension. It is a generally accepted view that the BK-induced BP lowering effect is mediated by the kinin B2 receptor, but B1 might also be involved under special situations[36]. It has been demonstrated that the B2 receptor antagonist (B5630) can abolish the hypotensive effects of BK as well as captopril, an ACE inhibitor[43]. This led to the proposal that the hypotensive action of ACE inhibitors might be due to the activation of the kinin B2 receptor[81,82]. The accumulation of BK after treatment with ACE inhibitors with subsequent release of $\mathrm{NO}$, prostaglandins, and $\mathrm{PGI}_{2}$ could account for the additional mediators released by these drugs in hypertensive patients. However, the use of BK antagonists can abolish the effectiveness of antihypertensive drugs; therefore, these drugs must be contraindicated in patients with hypertension.

\section{Cardiac Failure and Ischemia}

Cardiac failure and ischemia are the leading cause of death in the developed and many developing countries[83]. These conditions are considered as the new emerging epidemic of the third millennium[83]. The role of kinins in the heart did not receive much attention, despite the fact that it was shown earlier[84] that local and systemic administration of BK can increase coronary blood flow and improve myocardial metabolism. It is well known that ACE inhibitors limit ventricular dilatation, delay the progression of clinical symptoms, and improve mortality rate. These beneficial actions appear to be related to the reduced formation of Ang II, which results in a decreased growth response and attenuated pressure load[84]. In addition, the ability of ACE inhibitors to prevent kinins from enzymatic breakdown represents a relevant mechanism contributing to cardioprotection[85]. This concept fueled a series of studies demonstrating the presence of a local KKS in the heart[1,2,4]. The binding of kinins to endothelial $\mathrm{B} 2$ receptors leads to the release of $\mathrm{NO}$ and $\mathrm{PGI}_{2}$, exerting vasodilator, ischemic, antiproliferative effects and preserving myocardial stores of energy-rich phosphates and glycogen[86]. Kinins contribute to the maintenance of cardiovascular homeostasis by opposing the vasoconstrictor activity of Ang II[87]. Circumstantial evidence also suggests that a dysfunctional KKS may contribute to the pathogenesis of heart failure. In fact, reduced local kinin generation and blunted NO formation have been reported in microvessels of failing human hearts[88]. Furthermore, in dogs with pacing-induced congestive heart 
failure, selective blockade of B2 receptors by Hoe 140 reduces coronary blood flow and contractility, and increases left ventricular end diastolic pressure[89]. Thus, the reduced activity of the cardiac KKS may facilitate the development of cardiac failure. On the other hand, kinins are continuously released during cardiac hypoxia and ischemia[8,90]. They act as cardioprotective agents in perfusion and participate in the process of ischemic preconditioning[7,10]. There is evidence to suggest that BK infusion into coronary artery reduces significantly the severity of ischemia-induced arrhythmia in anesthetized dogs[90]. Studies undertaken in rats, dogs, and humans revealed that kinins are released under the conditions of ischemia and myocardial infarction[91,92,93,94]. This process may be an indicator of the role of kinin in protecting the heart at the time of myocardial infarction. This raised local kinin release might be able to exert a protective effect on the heart by activating signal transduction pathways generating $\mathrm{NO}$ and $\mathrm{PGI}_{2}$. Coronary artery ligation for shorter and longer duration in SHR and WKYR showed that administration of BK could increase the survival time of these rats[44,45]. This effect of BK was reverted by pretreatment with a specific B2 receptor antagonist[45]. In conclusion, these results support the hypothesis that KKS might be regarded as a prime mediator in protecting the heart in ischemic conditions. However, extensive investigations on the molecular biology and gene mapping of KKS in the heart during health and cardiovascular diseases can provide many questions to be answered regarding the significance of KKS in cardiovascular pathophysiology. This may allow us to develop KKS-based therapeutics for the cardiovascular diseases.

\section{Left Ventricular Hypertrophy}

Left ventricular hypertrophy (LVH) is regarded as an independent risk factor in hypertensive patients[3]. BK can counter the development of LVH in rats with hypertension produced by aortic banding[11]. This antihypertrophic effect of BK was abolished by treatment with B2 receptor antagonist and NO synthetase inhibitor. Thus, BK has a role in protecting the heart against developing $\mathrm{LVH}$ by releasing $\mathrm{NO}$ in this model of hypertension induced by aortic banding. In this regard, we have demonstrated for the first time that a lack of the cardiac KKS could be responsible for the induction of LVH in SHR and SHR with diabetes[2,3,4]. Therefore, it is suggested that the reduced cardiac tissue kallikrein and cardiac kininogen may be responsible for reduced BK generation in the heart. Therefore, deficient components of the KKS in the heart may be the cause of myocardial dysfunction in maintaining high BP and cardiac LVH. It is highly desired the stable compounds of KKS be developed in order to evaluate their efficacy and potency in cardiac failure, cardiac ischemia, as well as myocardial infarction. Recently, we have shown that, in hypertensive rats, BP reduction and regression of $\mathrm{LVH}$ with captopril treatment might be due to enhanced renal tissue kallikrein activity[93]. This may further support the view that tissue kallikrein may act as a cardioprotective agent. It has been recently proposed that kinins have modulatory effects in preventing myocardium ischemia[95,96]. It is of interest to note that Madeddu and coworkers[97] described the cardiac hypertrophy and microvascular deficit in kinin B2 receptor knockout mice. The different synergistic cardioprotective actions of the $\mathrm{BK}$ in the abnormal diabetic heart may indicate that the stimulation of the BK system might be a useful tool for treating cardiopathy caused by diabetes[98]. A recent study conducted in diabetic and hypertensive rats has proposed that higher plasma prekallikrein levels may be an indicator for predicting hypertension and LVH[99]. Furthermore, activation of BK2 receptor may promote antioxidant, anti-inflammatory properties in protecting against stroke, cardiovascular and renal diseases, and may serve as new drug targets for preventing and treating heart failure, vascular injury, end-stage renal disorders, and stroke in humans[100].

\section{CONCLUSION}

The evidence presented in this review suggests that the KKS has a greater role to play in the various pathophysiological processes of the cardiovascular system, such as hypertension, cardiac failure and 
ischemia, $\mathrm{LVH}$, and endotoxemia. There is activation of BK activity in endotoxemia. Under this situation, the inhibition of KKS activities by the application of the kallikrein inhibitors, B1 and/or B2 receptor antagonists, may be able to reverse the pathological consequences. It is of interest to state that there is the possibility of the up-regulation of the B1 and B2 receptors in these pathological conditions. On the other hand, it seems that there is deficient activity of the KKS in the pathological conditions of hypertension, cardiac ischemia, and development pf LVH. These pathological states may be due to genetic abnormality of the KKS or down-regulation of BK receptors. These diseases may be treated with the application of tissue kallikrein and/or use of specific BK receptor agonists. Furthermore, the mode of cardioprotective effect of ACE inhibitors might be mediated via KKS.

\section{REFERENCES}

1. Britos, J. and Nolly, H.L. (1981) Kinin-forming enzyme of rat cardiac tissue. Subcellular distribution and biochemical properties. Hypertension 3(6 Pt 2), II-42-55.

2. Sharma, J.N. and Uma, K. (1996) Cardiac kallikrein in hypertensive and diabetic rats with and without diabetes. Immunopharmacology 33, 341-343.

3. Sharma, J.N., Uma, K., and Yusof, A.P.M. (1998) Left ventricular hypertrophy and its relation to the cardiac kininforming system in hypertensive and diabetic rats. Int. J. Cardiol. 63, 229-235.

4. Sharma, J.N., Uma, K., and Yusof, A.P.M. (1999) Altered cardiac tissue and plasma kininogen levels in hypertensive and diabetic rats. Immunopharmacology 34, 129-132.

5. Oza, N.B. and Goud, H.D. (1992) Kininogenase of the aortic wall in spontaneously hypertensive rats. J. Cardiovasc. Pharmacol. 20(Suppl 9), 1-3.

6. Nolly, H.L., Carretero, O.A., and Sclicli, A.J. (1993) Kallikrein release by vascular tissue. Am. J. Physiol. 265, H1209-H1214.

7. Vegh, A., Szekeres, L., and Parratt, J.R. (1991) Local intracoronary infusions of bradykinin profoundly reduce the severity of ischaemia-induced arrhythmia in anaesthetized dogs. Br. J. Pharmacol. 104, 294-295.

8. Linz, W., Wiemer, G., and Scholkens, B.A. (1993) Bradykinin prevents left ventricular hypertrophy in rats. J. Hypertens. 11(Suppl 5), S96-S97.

9. Vegh, A., Rapp, J.G., and Parratt, J.R. (1994) Attenuation of the antiarrhythmic effects of ischaemia preconditioning by blockade of bradykinin B2 receptors. Br. J. Pharmacol. 107, 1167-1172.

10. Walls, T.M., Sheehy, R., and Hartman, J.C. (1994) Role of bradykinin in myocardial preconditioning. J. Pharmacol. Exp. Ther. 270, 681-689.

11. Linz, W., Wiemer, G., and Scholkens, B.A. (1993) Contribution of bradykinin to the cardiovascular effects of ramipril. J. Cardivasc. Pharmacol. 22(Suppl 9), S1-S8.

12. Sharma, J.N. (1984) Kinin-forming system in the genesis of hypertension. Agents Actions 14, $200-205$.

13. Sharma, J.N. (1988) Interrelationship between the kallikrein-kinin system and hypertension: a review. Gen. Pharmacol. 19, 177-187.

14. Sharma, J.N. (1989) Contribution of kinin system to the antihypertensive action of angiotensin converting enzyme inhibitors. Adv. Exp. Med. Biol. 247, 197-205.

15. Sharma, J.N., Uma, K., and Noor, A.R. (1996) Blood pressure regulation by the kallikrein-kinin system. Gen. Pharmacol. 27, 55-63.

16. Sharma, J.N. (1990) Does kinin mediate the hypotensive action of angiotensin converting enzyme (ACE) inhibitors? Gen. Pharmacol. 21, 451-457.

17. Sharma, J.N. (1992) Involvement of the kinin-forming system in physiopathology of rheumatoid inflammation. Agents Actions 38(III), 343-361.

18. Nagayasa, T. and Nagasawa, S. (1979) Studies of human kininogen. Isolation, characterization, and cleavage by plasma kallikrein of high molecular weight (HMW) kiniogen. J. Biochem. 85, 249-258.

19. Muller-Esterl, W., Iwanaga, S., and Nakanishi, S. (1986) Kininogens revisited. TIBS 11, 336-339.

Greenbaum, L.M. (1982) T-kinin and T-kininogen, children of technology. Biochem. Pharmacol. 33, $2943-2944$.

21. Okamoto, H. and Greenbaum, L.M. (1983) Pharmacological properties of T-kinin. Biochem. Pharmacol. 32, 26372638.

22. Nustad, K., Vaaje, K., and Pierce, J.V. (1975) Synthesis of kallikrein by rat kidney slices. Br. J. Pharmacol. 53, 229234.

23. Sharma, J.N., Zeitlin, I.J., Deodhar, S.D., and Buchanan, W.W. (1983) Detection of tissue kallikrein-like activity in inflamed synovial tissue. Arch. Int. Pharmacodyn. Ther. 262, 279-286.

24. Bhoola, K.D., Figueroa, C.D., and Worth, K. (1992) Bioregulation of kinin, kallikrein, kininogen and kininases. Pharmacol. Rev. 44, 1-80.

25. Takada, Y., Skidgel, R.A. and Erdos, E.G. (1985) Purification of human urinary prokallikrein: identification of the 
site of activation by the metalioprotinase thermolysin. Biochem. J. 232, 851-856.

26. Weiss, A.S., Gallin, J.L., and Kaplan, A.P. (1974) Fletcher factor deficiency: a diminished rate of Hageman factor activation caused by absence of prekallikrein with abnormalities of coagulation, fibrinolysis, chemotactic activity and kinin generation. J. Clin. Invest. 53, 622-633.

27. Cochrane, C.G., Revak, S.D., and Wuepper, D. (1973) Activation of Hageman factor in solid and fluid phase. A critical role of kallikrein. J. Exp. Med. 138, 1564-1583.

28. Griffin, J.H. and Cochrane, C.G. (1976) Mechanism for the involvement of high molecular weight kininogen in surface-dependent reactions of Hageman factor. Proc. Natl. Acad. Sci. U. S. A. 73, 2554-2558.

29. Mandle, R., Colman, R.W., and Kaplan, A. (1976) Identification of prekallikrein and high-molecular-weight kininogen as a complex in human plasma. Proc. Natl. Acad. Sci. U. S. A. 73, 4176-4183.

30. Thampson, R.E., Mandle, R., and Kaplan, A.P. (1977) Association of factor XI and high molecular weight kininogen in human plasma. J. Clin. Invest. 60, 1376-1380.

31. Silverberg, M. and Diehl, S. (1987) The autoactivation of factor XII (Hageman factor) induced by low-heparin and dextran sulfate. Biochem. J. 248, 715-720.

32. Woodley-Miller, C., Chao, J., and Chao, L. (1989) Restriction fragment length polymorphisms mapped in spontaneously hypertensive rats using kallikrein probes. J. Hypertens. 7, 865-871.

33. Pravenc, M., Ken, V., Kunes, J., Sclicli, G., Carretero, O.A., Simonet, L., and Kurtz, T.W. (1991) Cosegregation of blood pressure with a kallikrein gene family polymorphism. Hypertension 17, 242-246.

34. Erdos, E.G. (1990) Some old and some new ideas on kinin metabolism. J. Cardiovasc. Pharmacol. 15(Suppl 6), S20S24.

35. Marceau, F., Hess, J.F., and Bachvarov, D.R. (1998) The Bl receptors for kinin. Pharmacol. Rev. 50, $357-386$.

36. Regoli, D. (1984) Neurohumoral regulation of precapillary vessels: the kallikrein-kinin system. J. Cardiovasc. Pharmacol. 6(Suppl 3), S401-S412.

37. D’Orleans-Juste, P., de Nucci, G., and Vane, J.R. (1989) Kinins act on Bl or B2 receptors to release conjointly endothelium-derived relaxing factor and prostacyclin from bovine aortic endothelial cells. Br. J. Pharmacol. 96, 920926.

38. Tiffany, C.W. and Burch, M. (1989) Bradykinin stimulates tumor necrosis factor and interleukin-1 release from macrophages. FEBS Lett. 247, 189-192. Whalley, E.T., Clegg, S., Stewart, J.M., and Vavrek, R.J. (1987) The effect of kinin agonists and antagonists on the pain response of human blister base. Naunyn Schmiedeberg's Arch. Pharmacol. 336, 652-655.

40. Sharma, J.N. and Yusof, A.P.M. (1998) Pro-inflammatory properties of the kallikrein-kinin system: potential for new drug therapy. Inflammopharmacology 6, 289-296.

41. Sharma, J.N., Yusof, A.P.M., and Wirth, K.J. (1998) The kinin antagonist Hoe 140 reduces acute paw oedema in rats caused by carrageenan, bradykinin and kaolin. Inflammopharmacology 6, 9-17.

42. Jin, L.S., Seeds, E., Page, C., and Schachter, M. (1989) Inhibition of bradykinin-induced bronchoconstriction in guinea-pig by a synthetic B2 receptor antagonist. Br. J. Pharmacol. 97, 598-602.

43. Sharma, J.N., Stewart, J.M., Mohsin, S.S.J., Katori, M., and Vavrek, R. (1992) Influence of a kinin antagonist on acute hypotensive responses induced by bradykinin and captopril in spontaneously hypertensive rats. Agents Actions 38(III), 258-269.

44. Atif Abbas, S., Sharma, J.N., Pauzi, A., and Yusof, M. (1999) Effect of bradykinin and its antagonist on survival time after coronary artery occlusion in rats. Gen. Pharmacol. 33, 243-247.

45. Abbas, S.A., Sharma, J.N., and Yusof, A.P. (1999) The effect of bradykinin and its antagonist on survival time after coronary artery occlusion in hypertensive rats. Immunopharmacology 44, 93-98.

46. Barabe, J., Droulin, J.N., Regoli, D., and Park, W.K. (1977) Receptors for bradykinin in intestine and uterine smooth muscle. Can. J. Physiol. Pharmacol. 96, 920-926.

47. Farmer, S.G., Burch, R.M., Meeker, S.A., and Wilkins, D.E. (1989) Evidence for a pulmonary B3 bradykinin receptor. Mol. Pharmacol. 36, 1-8.

48. Saha, J.K., Sengupta, J.N., and Goyal, R.K. (1990) Effect of bradykinin on opossum longitudinal smooth muscle: evidence for novel bradykinin receptors. J. Pharmacol. Exp. Ther. 252, 1012-1020.

49. Saha, J.K., Sengupta, J.N., and Goyal, R.K. (1991) Effect of bradykinin and bradykinin analogs on the opossum lower esophageal sphincter: characterization of an inhibitory bradykinin receptor. J. Pharmacol. Exp. Ther. 259, $265-273$.

50. Regoli, D. and Barabe, J. (1980) Pharmacology of bradykinin and related kinins. Pharmacol. Rev. 32, 1-46.

51.

Wirth, K.J., Hock, F.J., Albus, U., Linz, W., Alphermann, H.G., Anagnostopoulos, H., and Scholkens, B.A. (1991) Hoe 140 a new potent and long acting bradykinin antagonist-in vitro studies. Br. J. Pharmacol. 102, 774-777.

52. Cheronis, J.C., Whally, E.T., and Nguyen, K.T. (1992) A new class of bradykinin antagonist: synthesis and in vitro activity of bissuccinimidoalkane peptide dimmers. J. Med. Chem. 35, 1563-1572.

53. Hanson, L., McCullough, R.G., and Selig, W.M. (1996) In vivo pharmacological profile of novel, potent, stable BK antagonist at B1 and B2 receptors. Immunopharmacology 33, 191-193.

54. Burgess, G.M., Perkins, M.N., Rang, P.R., Campbell, E.A., Brown, M.C., McIntyre, P., Urban, L., Dziadulewicz, E.K., Ritchie, T.J., Hallett, A., Snell, C.R., Wrigglesworth, R., Lee, W., Davis, C., Phagoo, S.B., Davis, A.J., Phillips, E.P., Darke, G.S., Hughes, G.A., Dusten, A., and Bloomfield, G.C. (2000) Bradyzide, a potent non-peptide B2 bradykinin receptor antagonist with long-lasting oral activity in animal models of inflammatory hyperalgesia. Br. $J$. 
Pharmacol. 129, 77-86.

55. Farmer, S.G. and Burch, R.M. (1992) Biochemical and molecular pharmacology of kinin receptors. Annu. Rev. Pharmacol. Toxicol. 32, 511-536.

56. Burch, R.M. (1990) Kinin signal transduction: role of phosphoinositides and eicosanoids. J. Cardiovasc. Pharmacol. 15(Suppl 6), S44-S46.

57. Sharma, J.N. and Zeitlin, I.J. (1977) Indomethacin in low concentrations potentiates the action of some spasmogens on the isolated oestrous rat uterus. J. Pharm. Pharmacol. 29, 316-317.

58. Akbar, A., Sharma, J.N., Yusof, A.P., and Gan, E.K. (1998) Potentiation of bradykinin-induced responses in the intact and denuded epithelium of guinea pig tracheal preparations. Int. J. Tissue React. 20(3), 95-100.

59. $\quad$ Ransom, R.W., Young, G.S., Schneck, K., and Goodman, C.B. (1992) Characterization of solubilized bradykinin B2 receptors from smooth muscle and mucosa of guinea-pig ileum. Biochem. Pharmacol. 43, 1823-1827.

60. Schini, V.B., Boulanger, C., Regoli, D., and Vanhoutte, P.M. (1990) Bradykinin stimulates the production of cyclic GMP via activation of B2 receptors in cultured porcine aortic endothelial cells. J. Pharmacol. Exp. Ther. 252, 581585.

61. Fischer, L.G., Hollmann, M.W., Horstaman, D.J. and Rich, G.F. (2000) Cyclooxygenase inhibitors attenuate bradykinin-induced vasoconstriction in septic isolated lung. Anesth. Analg. 90, 625-631.

62. De Freitas, F.M., Farraco, E.Z., and De Azevedo, D.F. (1964) General circulatory alterations induced by intravenous infusion of synthetic bradykinin in man. Circulation 29, 66-70.

63. Webster, M.E. and Gilmore, J.P. (1964) Influence of kallidin-10 on renal function. Am. J. Physiol. 206, 714-718.

64. McGiff, J.C., Itskovitz, H.D., and Terrango, N.A. (1975) The action of bradykinin and eledoicin in the canine isolated kidney: relationship to prostaglandins. Clin. Sci. Mol. Med. 49, 125-131.

65. Margolius, H.S., Geller, R., Pisano, J.J., and Sjoerdsma, A. (1971) Altered urinary kallikrein excretion in human hypertension. Lancet 2, 1063-1065.

66. Margolius, H.S., Geller, R., deJong, W., Pisano, J.J., and Sjoerdsma, A. (1972) Altered urinary kallikrein excretion in rats with hypertension. Circ. Res. 30, 358-362.

67.

68. Sharma, J.N. and Zeitlin, I.J. (1981) Altered plasma kininogen in clinical hypertension. Lancet 1, 125-126.

Sharma, J.N. (1988) Kinin system and prostaglandins in the intestine. Pharmacol. Toxicol. 63, 310-316.

69. Almeida, F.A., Stella, R.C.R., Voos, A., Ajzen, H., and Riberio, A.B. (1981) Malignant hypertension: a syndrome associated with low plasma kininogen and kinin potentiating factor. Hypertension 3, 46-50.

70. James, F.W. and Donaldson, V.H. (1981) Decrease exercise tolerance and hypertension in serve hereditary deficiency of plasma kininogen. Lancet 1, 889.

71. Mohsin, S.S.J., Majima, M., Katori, M., and Sharma, J.N. (1992) Important suppressive roles of the kallikrein-kinin system during the developmental stage of hypertension in spontaneously hypertensive rats. Asia Pacific J. Pharmacol. 7, 73-82.

72. Katori, M. and Majima, M. (1997) Role of the renal kallikrein-kinin system in the development of hypertension. Immunopharmacology 36, 237-242.

73. Wang, C., Chao, L., and Chao, J. (1994) Human tissue kallikrein induces hypotension in transgenic mice. Hypertension 23, 236-243.

74. Sharma, J.N., Amrah, S.S., and Noor, A.R. (1995) Suppression of hypotensive responses of captopril and enalapril by kallikrein inhibitors aprotinin in spontaneously hypertensive rats. Pharmacology 50, 363-369.

75. Chao, J. and Chao, L. (1998) Kallikrein gene therapy in hypertension, cardiovascular and renal diseases. Gen. Ther. Mol. Biol. 1, 301-308.

76. Silberbauer, K., Stanek, B., and Temple, H. (1982) Acute hypotensive effect of captopril in man modified by prostaglandian synthesis inhibition. Br. J. Clin. Pharmacol. 14, 87S-93S.

77. Antonaccio, M. (1982) Angiotensin converting enzyme (ACE) inhibitors. Annu. Rev. Pharmacol. Toxicol. 22, $57-87$.

78. Sharma, J.N., Ferandez, P.G., Kim, B.K., and Triggle, C.R. (1984) Systolic blood pressure responses to enalapril maleate (MK 421), an angiotensin converting enzyme inhibitor and hydrochlorothiazide in conscious Dahl saltsensitive (S) and salt-resistant (R) rats. Can. J. Physiol. Pharmacol. 62, 241-243.

79. Edery, H., Rosenthal, T., Amitzur, G., Rubinstein, A., and Stern, N. (1981) The influence of SQ 20881 on the blood kinin system of renal hypertensive patients. Drug Exp. Clin. Res. VII, 749-756.

80. Smith, C., Campbell, S., and Albano, J. (1990) Urinary kallikrein excretion in normotensive and hypertensive pregnancies: 8 years later. Immunopharmacology 44, 177-182.

81. Sharma, J.N. (1993) Therapeutic prospects of bradykinin antagonists. Gen. Pharmacol. 24, 267-274.

82. Branuwald, E. (1997) Cardiovascular medicine at turn of the millennium: triumphs, concern and opportunities. $N$. Engl. J. Med. 337, 1360-1369.

83. Lochner, W. and Parratt, J.R. (1966) A comparison of the effects of locally and systemically administered kinin on coronary blood flow and myocardial metabolism. Br. J. Pharmacol. Chemother. 26, 17-26.

84. Linz, W., Wiemer, G., and Gohlke, P. (1995) Contribution of kinin to the cardiovascular action of converting-enzyme inhibitors. Pharmacol. Rev. 47, 25-50.

85. Zhu, P., Zugga, C.E., Simper, D., Hornstein, P., Allegrini, P.R., and Buser, P.T. (1995) Bradykinin improves postischaemic recovery in the rat heart: role of high energy phosphates, nitric oxide and prostacyclin. Cardiovasc. Res. 29, 658-663. 
86. Madeddu, P., Milia, A.F., Salis, M.B., Gaspa, L., Gross, W., Lippoldt, A., and Emanueli, G. (1998) Renovascular hypertension in bradykinin B2-receptor knockout mice. Hypertension 23, 305-509.

87. Kichuck, M.R., Seyedi, N., Zhang, X., Marboe, C.C., Michler, R.E., Addonzio, L.J., Kaley, G., Nasjletti, A., and Hintze, T.H. (1996) Regulation of nitric acid production in human coronary microvessels and the contribution of local kinin formation. Circulation 94, 44-51.

88. Whalley, E.T., Soomon, J.A., and Modafferi, D.M. (1992) CP-0127, a novel potent bradykinin antagonist increases survival in rat and rabbit model of endotoxin shock. Agents Actions 38(Suppl), 431-420.

89. Koide, A., Zeitlin, I.J., and Parratt, J.R. (1993) Kinin formation in ischaemic heart and aorta of anaesthetized rats. J. Physiol. (Lond.) 467, 125P.

90. Scholkens, B.A. (1996) Kinins in the cardiovascular system. Immunopharmacology 33, 209-217.

91. Rubin, L.E. and Levi, R. (1995) Protective role of bradykinin in cardiac anaphylaxis. Coronary-vasodilating and antiarrhythmic activities mediated by autocrine/paracrine mechanisms. Circ. Res. 79, 434-440.

92. Yoshida, H., Zhang, J.J., Chao, L., and Chao, J. (2000) Kallikrein gene delivery attenuates myocardial infarction and apoptosis after myocardial ischaemia and perfusion. Hypertension 35, 25-31.

93. Sharma, J.N. and Kesavarao, U. (2002) Effect of captopril on urinary kallikrein, blood pressure and myocardial hypertrophy in diabetic spontaneously hypertensive rats. Pharmacology 64, 196-200.

94. Dela Cadena, R.A., Suffredini, A., Page, J.D., Pixley, R.A., Kaufman N., Parrillo, J.E., and Colman, R.W. (1993) Activation of kallikrein-kinin system after endotoxin administration to normal human volunteers. Blood 81, 33133317.

95. Nies, A.S., Forsyth, R.P., Williams, H.E., and Melmon, K.L. (1968) Contribution of kinins to endotoxin shock in unanesthetized Rhesus monkeys. Circ. Res. 22, 155-164.

96. Marcondes, S.E and Antunes, E. (2005) The plasma and tissue kininogen-kallikrein-kinin system: role in cardiovascular system. Curr. Med. Chem. 3, 33-44.

97. Maestri, R., Milia,. AF., Salis, M.B, Graiani, G., Lagrasta, C, Monica, M., Corr, D., Emanueli, C., and Madeddu, P. (2003) Cardiac hypertrophy and microvascular deficit in kinin B2 receptor knockout mice. Hypertension 41, 11511155.

98. Spillmann, F., Van Linthout, S., Schultheiss, H.P., and Tschope, C. (2006) Cardioprotective mechanisms of the kallikrein-kinin system in diabetic cardopathy. Curr. Opin. Nephrol. Hypertens. 15, 22-29.

99. Sharma, J.N. and Kesavarao, U. (2007) Changes in plasma prekallikrein activity, blood pressure, and left ventricular thickness in hypertensive and normotensive diabetic rats. Methods Find. Exp. Clin. Pharmacol. 29, 75-78.

100. Chao, J. and Chao, L. (2004) Kallikrein-kinin in stroke, cardiovascular and renal disease. Exp. Physiol. 90, $291-298$.

\section{This article should be cited as follows:}

Sharma, J.N. (2008) Cardiovascular activities of the bradykinin system. TheScientificWorldJOURNAL 8, 384-393. DOI 10.1100/tsw.2008.53. 


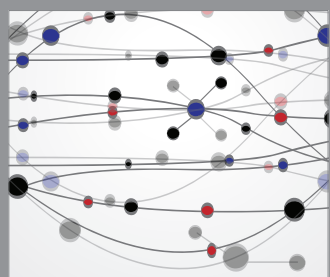

The Scientific World Journal
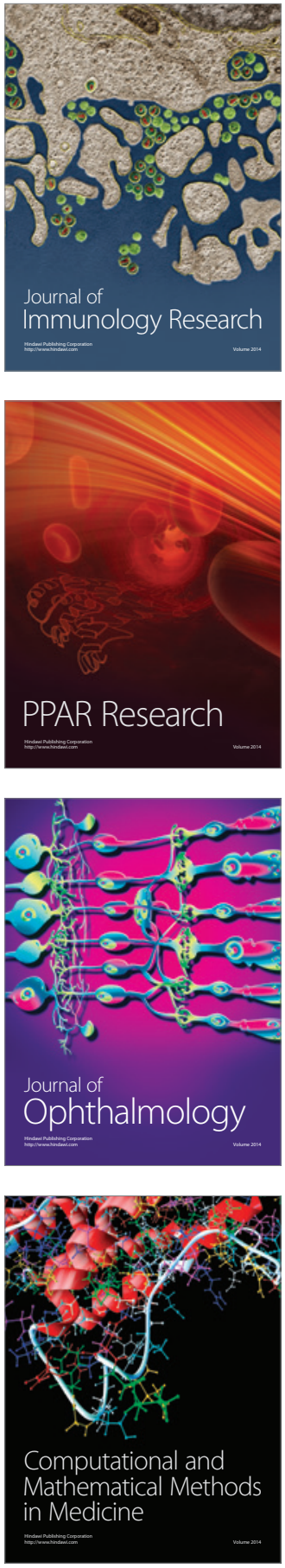

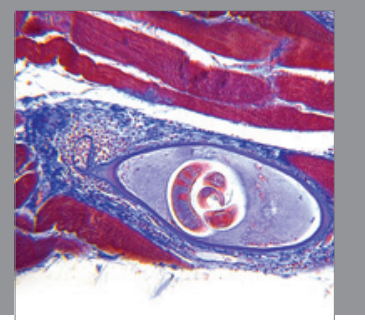

Gastroenterology

Research and Practice
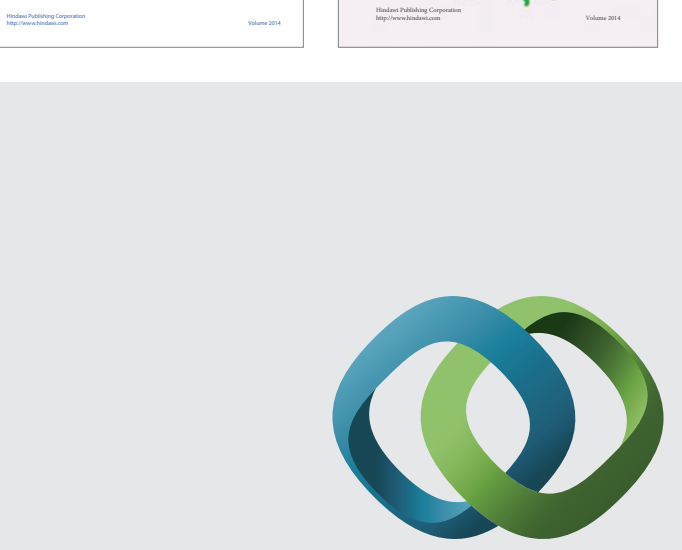

\section{Hindawi}

Submit your manuscripts at

http://www.hindawi.com
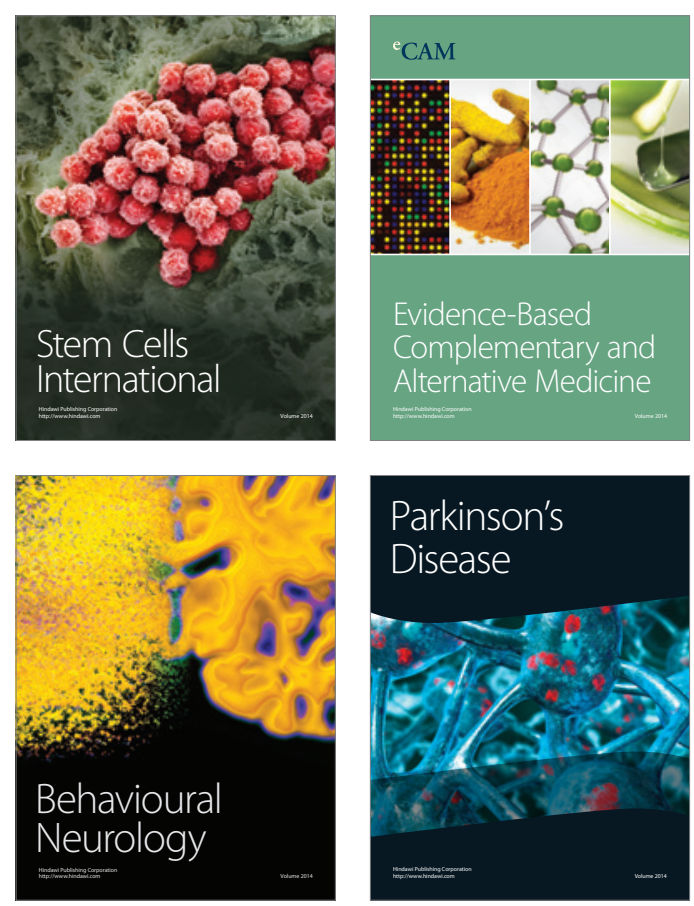

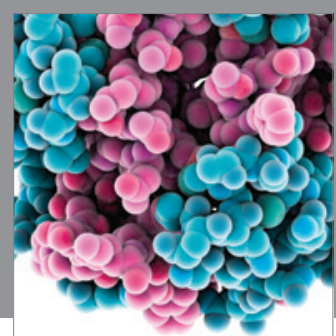

Journal of
Diabetes Research

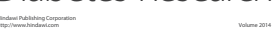

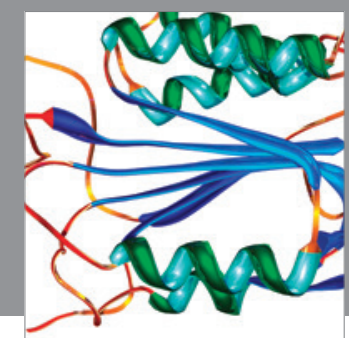

Disease Markers
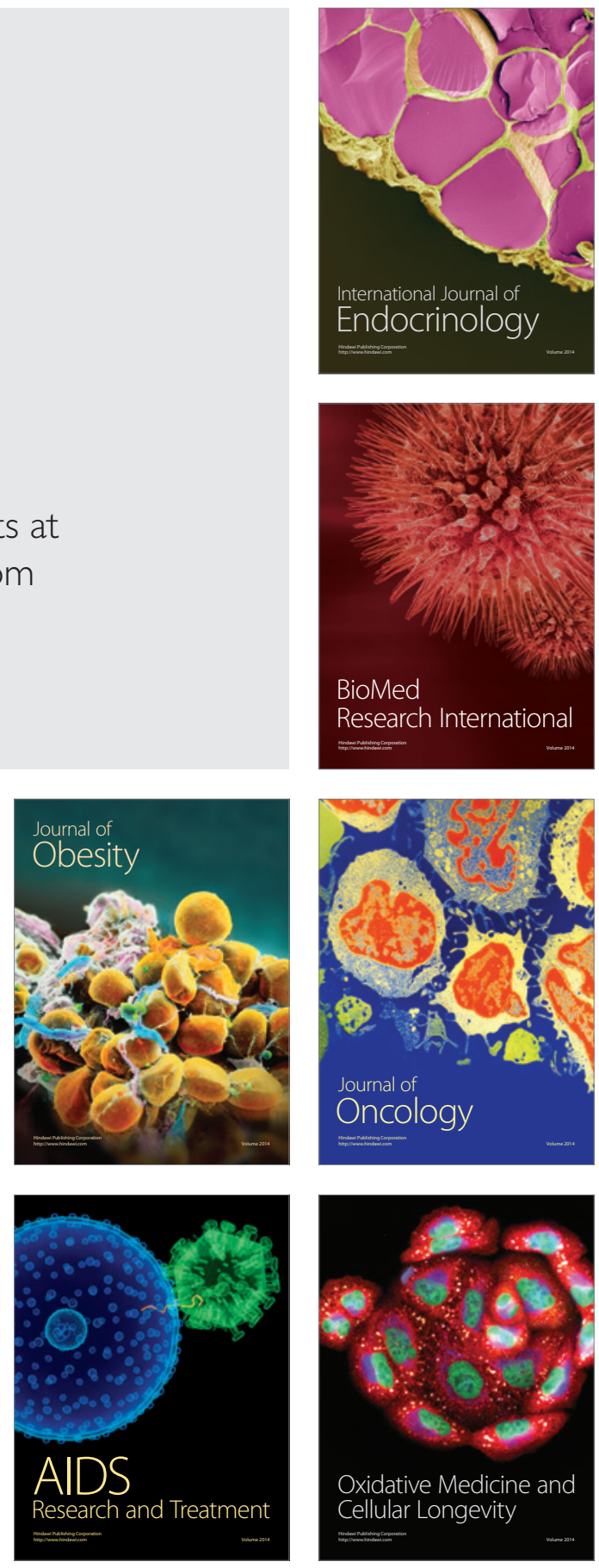